\title{
Experience of solar-diesel power plant introduction in the village of Nerkha of the Irkutsk region
}

Irina Ivanova*, and Timofei Pasechnikov, Melentiev Energy Systems Institute of Siberian Branch of the Russian Academy of Sciences, Irkutsk, Russia

\begin{abstract}
The paper presents a brief characteristic of the state of power supply to the consumers of the village of Nerkha in the Nizhneudinsk Area of the Irkutsk Region before the construction of a solar power plant. The main principles of the feasibility study on construction of a solar-diesel power plant are described. The schedules of the calculated power generation by the photovoltaic modules on the basis of the data of the local meteorological station are compared with the actual consumption schedule. The connection diagram of the solar-diesel power plant components is shown and its operating principle is briefly described. The actual data of power generation by the diesel power plant and photovoltaic modules for five months of operation are presented. The calculated and actual indices are compared. Keywords: Diesel power plant, photovoltaic modules, battery inverters, network inverters, power consumption, calculated generation
\end{abstract}

\section{Introduction}

At present the zone of decentralized power supply in the Irkutsk Region includes about 67 settlements numbering above 10 thousand people. The total capacity of diesel power plants (DPPs) supplying power to the consumers of this zone is more than $21 \mathrm{MW}$, the average fuel component in power production cost is estimated at $20 \mathrm{RUB} / \mathrm{kWh}$. The main problems in power supply in this zone are the difficult conditions of fuel delivery and the state of energy equipment. Many diesel generators were worn-out and obsolete. The everoccurred numerous failures of equipment lead to interruptions in its operation and additional expenditures. The common problem of the majority of similar isolated settlements is the outdated distribution networks and the noncompliance with the standard wire sections, the losses at the old overloaded transformer substations, etc. The supplied power is not accounted for most frequently.

The villages of Nerkha, Alygdzher, Verkhnyaya Gutara located in the hard-to-reach place of the Nizhneudinsk Area are the isolated settlements of the Irkutsk Region. The population numbers 1168 people or 358 physical power consumers. The capacity of diesel generators used for power supply in the villages ranges from 160 to $300 \mathrm{~kW}$. The inaccessibility of the villages causes serious problems in delivery of fuel, equipment and materials for maintenance operations. In two settlements all cargoes are delivered by winter

* Corresponding author: nord@isem.irk.ru 
roads. The fuel cost and transportation charges, as well as the costs on generator maintenance and replacement increase year by year. Meanwhile, the cost of alternative energy sources, particularly solar installations, decreases in the world year by year practically twofold.

\section{Description of power supply state in the village of Nerkha}

The village of Nerkha was chosen as the primary location for a solar power plant, where the cost of power production at DPP was estimated at $24.5 \mathrm{RUB} / \mathrm{kWh}$, including the costs on operation, depreciation, fuel delivery and maintenance. There were many problems in the power supply to consumers of the village. The $0.4 \mathrm{kV}$ distribution network was in an emergency state, in many parts of the electric network there were so-called "links" - wires with a smaller section. Diesel generators frequently broke down due to the unsatisfactory technical state and operating conditions. There was no fire protection system at all. Due to the problems with the wire section and the natural constant growth of power consumption, the voltage on the network parts that were far from DPP was reduced to $150-180 \mathrm{~V}$, which is unacceptable for high-quality power supply to consumers. DPP was located in the very central part of the village, and a constant noise for 16 hours every day was the usual life situation. The room, in which DPP was located, did not correspond to normal conditions the building was outdated long ago.

The increased power consumption was caused not only by high network losses due to the non-standard wire section, the lack of transformer substations and electricity meters, but also the uneven distribution of the DPP load. For example, in the summer period the 160 $\mathrm{kW}$ DPP was loaded only up to $15-20 \mathrm{~kW}$, which led to a decrease in efficiency and an increase in specific fuel consumption. All of the above factors caused excessive expenditures for fuel and DPP repairs, and worsened the conditions for power supply to consumers.

Table 1 presents the main technical and economic indices of DPP in the village of Nerkha.

Table 1. Technical and economic indices of DPP

\begin{tabular}{|c|c|}
\hline Index & Value \\
\hline Installed capacity of DPP, $\mathrm{kW}$ & 160 \\
\hline Power generation, thousand $\mathrm{kWh} /$ year & 398.9 \\
\hline Operating costs, million RUB/year & 9.78 \\
\hline Power production cost, RUB/kWh & 24.5 \\
\hline Annual fuel consumption, $\mathrm{t}$ & 150 \\
\hline
\end{tabular}

\section{Feasibility study of solar-diesel power plant construction}

The feasibility study of the project "Modification of the power supply system in the villages of Nerkha, Alygdzher, Verkhnyaya Gutara in Tofalaria with construction of generating facilities on renewable energy sources" that was carried out by LLC "BaikalRemPutMash" (Slyudyanka town) (LLC "BRPM") presented and analyzed the options for solving the above problems and improving of the efficiency of power supply to consumers.

Based on the analysis of the archive of wind speed measurements by the local meteorological stations, it was concluded that the construction of wind power plants in the considered villages was ineffective. 
By virtue of the seasonal changes in the length of the daytime, it was determined that the maximum possible fuel savings during the year due to photovoltaic modules (PVMs) could be $50 \%$. However, the generator service life will be significantly greater subject to the sufficient marginal capacity of storage batteries. In order to provide the maximum efficiency of the solar power plant, the required capacity of the photovoltaic modules was selected so that the excess power from the solar arrays was minimal. The required calculated capacity of photovoltaic modules is no less than $120 \mathrm{~kW}$ and the capacity of storage batteries is $864 \mathrm{kWh}$. The indices of the main equipment of the solar-diesel power plant are given in Table 2.

Table 2. Unit commitment of the solar-diesel power plant in the village of Nerkha

\begin{tabular}{|l|c|}
\hline \multicolumn{1}{|c|}{ Index } & Value \\
\hline Capacity of PVM, W & 270 \\
\hline Type of module & Mono crystal \\
\hline Number of PVMs, pcs. & 450 \\
\hline Total capacity of PVMs, kW & 121,5 \\
\hline Type of storage batteries & OPzV \\
\hline Number of storage batteries, pcs. & 144 \\
\hline Capacity of storage batteries, $\mathrm{kWh}$ & 864 \\
\hline Capacity of battery inverters, $\mathrm{kW}$ & 108 \\
\hline Capacity of DPP, kW & 160 \\
\hline Inclination angle of PVMs (summer/autumn-spring/winter), degrees & $25 / 45 / 75$ \\
\hline
\end{tabular}

The solar radiation indices of the nearby local meteorological station "Khadama" were applied to estimate the possible power generation by photovoltaic modules, considering the shadows caused by the elevations of the terrain at a particular point of the solar power plant (Fig. 1). Fig. 2 and Table 3 show the share of calculated power generation by the photovoltaic modules in demand throughout the year. In winter, it is $14-31 \%$, in summer it reaches $84-88 \%$.

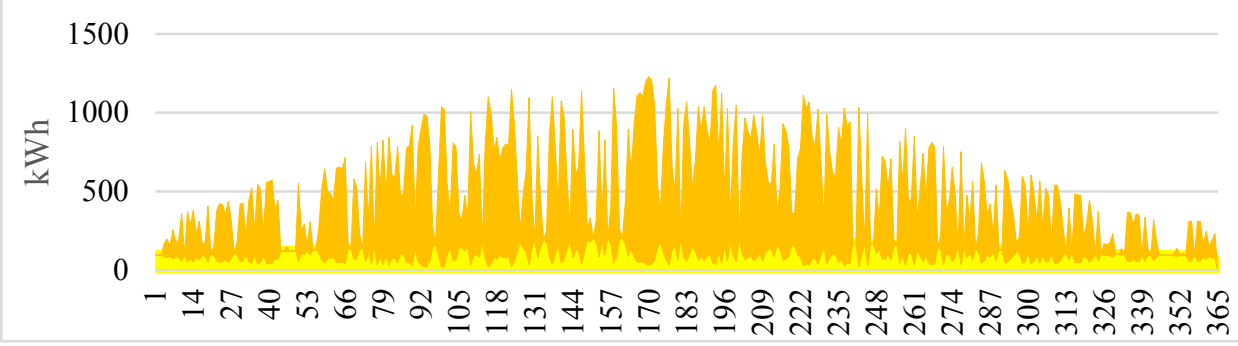

Fig.1.Calculated daily possible power generation by the photovoltaic modules with a capacity of $121.5 \mathrm{~kW}$ 


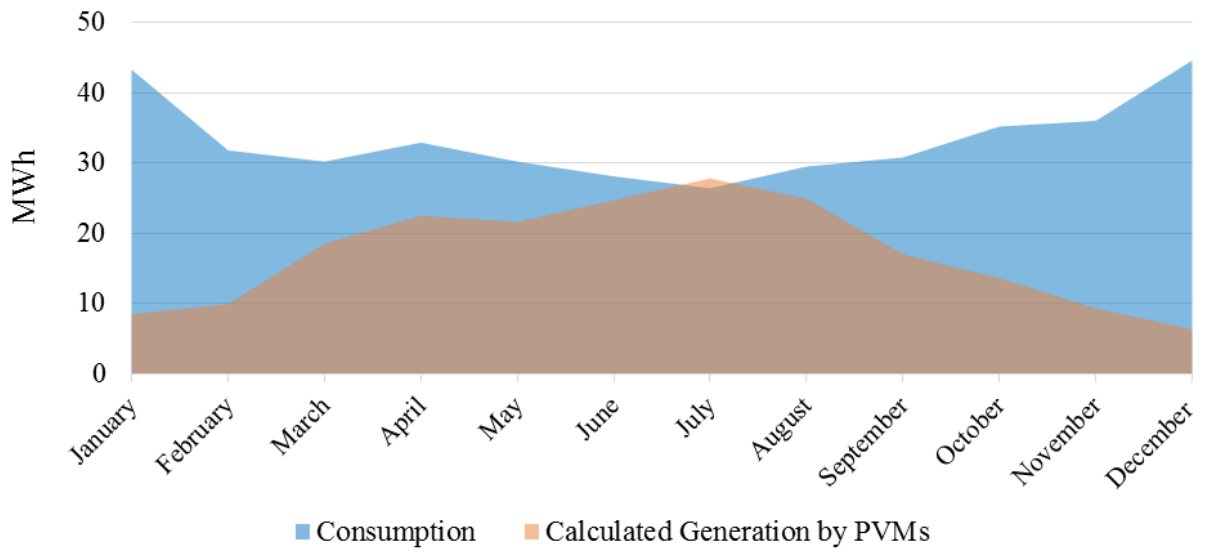

Fig. 2. Comparison of power consumption and calculated generation by photovoltaic modules

Table 3. Share of calculated indices of generation by photovoltaic modules with a capacity of $121.5 \mathrm{~kW}$ in power consumption in the village of Nerkha

\begin{tabular}{|l|c|c|c|c|c|c|c|c|c|c|c|c|}
\hline \multirow{2}{*}{ Index } & \multicolumn{10}{|c|}{ Month of year } \\
\cline { 2 - 12 } & 1 & 2 & 3 & 4 & 5 & 6 & 7 & 8 & 9 & 10 & 11 & 12 \\
\hline $\begin{array}{l}\text { Generation by PVMs, } \\
\text { thousand kWh }\end{array}$ & 8.5 & 9.9 & 18.5 & 22.5 & 21.6 & 24.7 & 27.8 & 24.9 & 17.0 & 13.6 & 9.3 & 6.3 \\
\hline $\begin{array}{l}\text { Consumption, } \\
\text { thousand kWh }\end{array}$ & 43.3 & 31.8 & 30.2 & 32.9 & 30.2 & 28.1 & 26.4 & 29.5 & 30.8 & 35.2 & 36.0 & 44.6 \\
\hline $\begin{array}{l}\text { Share of PVMs in } \\
\text { consumption, \% }\end{array}$ & 20 & 31 & 61 & 69 & 71 & 88 & 105 & 84 & 55 & 39 & 26 & 14 \\
\hline
\end{tabular}

The connection diagram of all components of the solar-diesel power plant allows combining the capacities of a diesel generator, storage batteries and photovoltaic modules (Fig. 3). When storage batteries and a diesel generator operate jointly, the total rated capacity will be $228 \mathrm{~kW}$. The function of uniform distribution of the generator load allows the rated capacity of $120 \mathrm{~kW}$ to be maintained at the generator output due to battery inverters using the excess power for charging. The generator capacity should be reduced, because the generator with such a load can continuously operate for more than 10 hours (for example, in December). The charging capacity of storage batteries varies depending on the consumer load. If it exceeds the generator capacity, the storage batteries cover it by discharging. If charged completely, the storage batteries with a maximum capacity of 108 $\mathrm{kW}$ can generate more than $540 \mathrm{kWh}$ for five hours with a $30 \%$ discharge. 


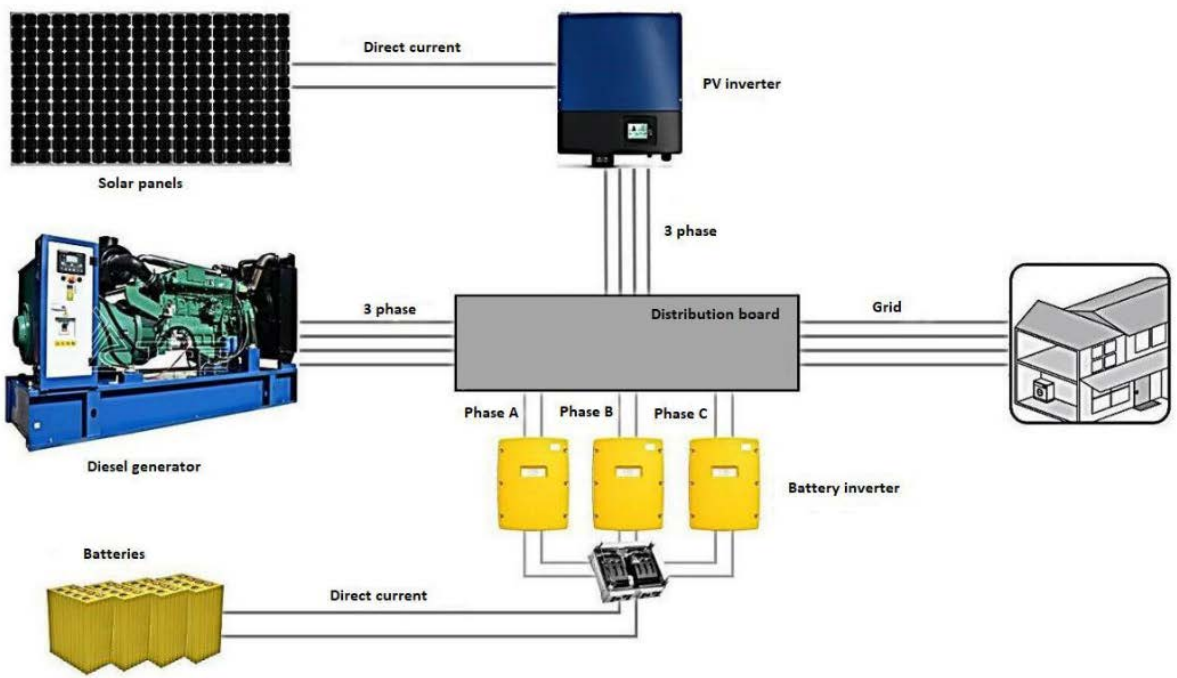

Fig. 3. Connection diagram of the solar-diesel power plant

\section{Operating experience of the solar-diesel power plant}

The solar power plant was commissioned on December 1, 2017. The load of DPP and PVMs was shifted automatically. The delivery of materials was the main problem of construction. Installation of the solar power plant, connection and commissioning works did not create difficulties. During operation, it turned out that the most important part was to monitor the storage batteries. Due to the equipment complexity, LLC "BRPM" conducts the daily information support via the Internet and the monitoring of the compliance with charge-discharge cycles, temperature of batteries and other indices. In addition to the solar power plant construction and the complete reconstruction of the $10 \mathrm{kV}$ networks, the company installed the smart electricity meters for each consumer. Fig. 4 shows a graph of the actual power generation by DPP and PVMs for the period from December 2017 to April 2018. The solar-diesel power plant performance during the day is available on the Internet at http://anga3.ru (Fig. 5).

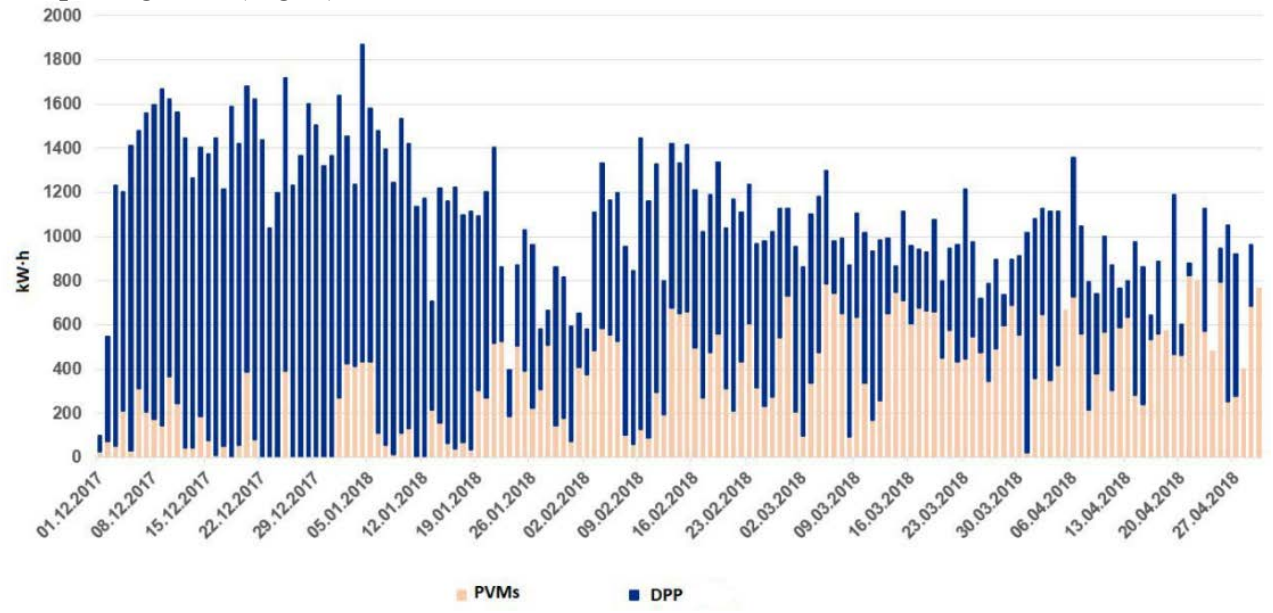

Fig. 4. Daily power generation by the solar-diesel power plant 


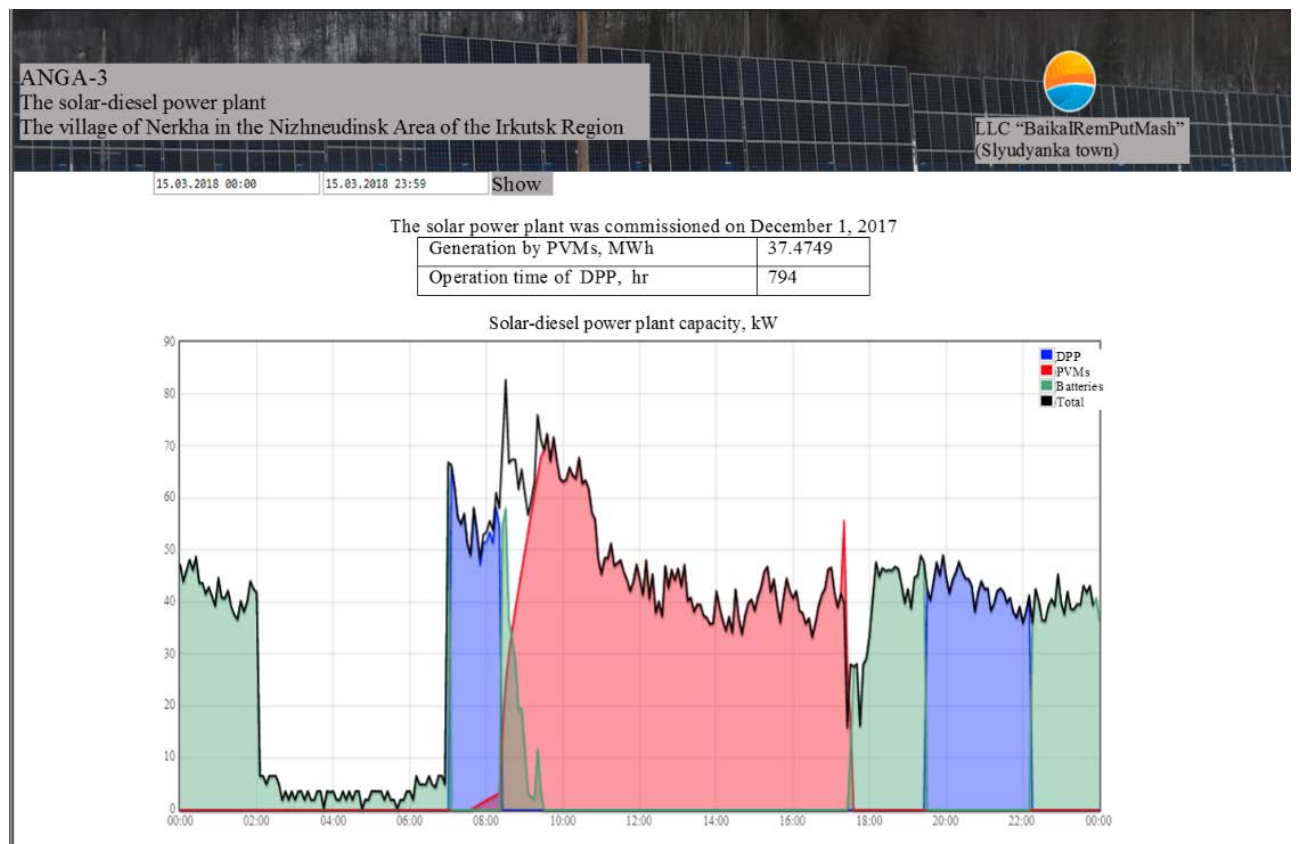

Fig. 5. Window of website anga3.ru as of 15.03.2018

According to the data as of May 1, 2018 the achieved indices are:

- the photovoltaic modules generated 45.13 thousand $\mathrm{kWh}$;

- the time of the diesel power plant operation was 1004 hours out of 3515 hours of power supply to consumers.

\section{Conclusions}

The comparative analysis of the calculated data from the feasibility study and the actual data on solar-diesel power plant operation in the village of Nerkha of the Nizhneudinsk Area revealed the comparability of indices. According to the data of the feasibility study, the photovoltaic modules were planned to generate 65.7 thousand $\mathrm{kWh}$ of power for the period from December through April, in practice their generation is estimated at 45.13 thousand $\mathrm{kWh}$. The economic effect for 5 months amounted to almost 800 thousand RUB owing to the substitution of 14.2 tons of diesel fuel.

\section{Acknowledgements}

Research was partially supported by the RFBR grants No. 17-48-380002. 